was ten grains of rhubarb, and ten of cordial confection, every day, till the stools became natural; and that this mode of treatment never failed." Should the gentle mode of treatment never be adopted, I think I may positively assert that peritoneal or puerperal fever would rarely, if ever, be treated with success; and I think it may be very fairly inferred, without any deterioration of the character of Dr. Butler, that he never had, in his great extent of practice, seen a single case of real peritoneal fever, though some. thing nearly resembling it. In the year 1787, puerperal fever raged in London. Dr.J. Clark says, " bleedıng was injurious; leeches to the abdomen were useless; emetics were hurtful; bark and cordials, though indicated by debility, were ineffica. cious. Dr. Lowder, who lectured about thirty years ago at the medical school of Guy's Hospital, relates two cases which were cured by taking a gallon of the decoc. tion of bark daily. Latterly, according to Dr. Armstrong, every patient who was not bled at the commencement, died; in Dr. Lowder's time, every patient who was bled, died. Now, had the same plan of treatment been adopted with Dr. Clark's patients as secommended by Dr. Armstrong, I believe the results would still have been unsuccessful; for the former appeared under a specific or malignant type, accompanied with great depression of the animal powers, with a pulse beating 160 or 170 in a minute, small, and soft. In these cases, death not unfrequently takes place in twenty hours. "Do what you will," said my worthy and muchesteemed preceptor, Dr. Blundell, "s the patient will die." The free use of the lancet is, in such cases, death. Mercury and turpentine are the best remedies; but, in the Jess severe form, a little blood may be taken. Whilst, in the latter, the fever was simple, attended with inflammation of the peritoneum, which, if attacked at the onset by bleeding, and the free exhibition of mercury, will, in general, prove successful; for bleeding early and freely in this form, is a sine qua non. The two cases I have related were evidently of the simple form; and by the active treatment adolsted, recorered. The efficacy of calomel in the latter case, particularly, was very striking; for, until the effect of the mercury was visible upon the submaxillary gland, (where it first shows itself,) the pulse still bore an inflammatory character, but which immediately subsided when the mouth became tender.

I beg to apologise for occupying so much of your valuable space, and the reader's time; and conclude by quoting Dr. Armstrong's observation upon the efficacy of mercury: "In a very few of those cases in which I gave calomel as a purgative, the gums became sore, and these recovered with unusual celerity." I have the honour ta be, Sir, your obedient servant,

34, Castle Street, Holborn, Oct. 19, 1829.

W. Durton.

CASES DEMONSTRATIVE OF THE EFFICACY OF THE ERGOT OF RYE.

By T. Calvert Girtsn, Esq. M.R.C.S.

BrEvitr, Sir, should ever characterise those productions which are deemed worthy of insertion into your valuable periodiens. Acting upon this principle, I have submitted to your observation, and to the notice of the profession generally, a few cases indicative of the great therapeutic agency of the secale cornutum, in further corroboration (if any be wanting) of the rast body of evidence now on record, relative to the efficacy of this remedy. I wish to observe, that the ergot of rye made use of on all these occa. sions, has been in my possession nearly four years. This substance has been supposed not to keep well; and a short time ago, in one of your Numbers, a communication was made upon the subject, in which it was said, that it would not keep good more than twelvemonths.

Mrs. B mother of six children, taken with labour in the usual manner, continued about four hours, when the pains gradually and completely subsided. Os uteri dilated larger than the circumference of a dollar. Ergot in powder, $3^{\text {ss. administered, which }}$ in twenty minutes produced a pain, shortly followed by another, and in half an hour, with consecutive increasing pain, the child was born. Placenta expelled in a short time, and the patient did well.

Mrs. K., mother of two children; pains began alsout eight in the evening; continued steadily improving till about one, when they slackened, and continued feeble and ineffective for three hours, the child making no advance, and the os uteri well dilated. Ergot given in powder, grs.xxv.; in 10 minutes a decided improvement had taken place, the pains powerfully increased, and the child was boin in forty minutes from the administration of the powder. Placenta came away naturally, and the case terminated well.

Mrs. C. The patient had five children, and on the birth of each, had suffered severely with lingering and complicated la. bours. Was of a consumptive habit. About the time she had reckoned upon being delivered, was seized suddenly with a profuse hæmorrhage while making water. The chamber-pot was filled with blood in an instant, and the bleeding continued in a mitigated stream till my arrival. Cold appli- 
cations to the vulva had a partial effect in allaying the hremorrhage, but a full dose of the ergot, ( $\ni i j$. by guess), in addition to the external remedies, completely checked the flow of blood, and brought on slight pains, which speedily improved to forcible and effective uterine contraction. The progress of parturition went steadily on for three or four hours, when the mouth of the womb, being dilated to the size of the brim of a tea-cup, the pain almost entirely went off. Ergot, $9 j$. in powder, brought the labour to a speedy conclusion; in an hour after its exhibition, the foetus and placenta were expelled. Case terminated favourably at the time, though the mother has since died from pulmonary consumption.

Mrs. R., at her first labour, was delivered of twins, which proceeded as usual. On the second occasion, the uterine efforts were feeble, and at long intervals throughout, and so continued for many hours, without any corresponding advance of the child commensurate with the open state of the uterus. A moderate dose of ergot improved the pains in frequency, though not in power, and in an hour after the first administration, a second dose, the same quantity as the former, was given; this in twenty minutes produced a full stimulant effect, and from that time the parturient efforts continued steadily till their final termination, in fifty minutes from the second dose of the secale. A favourable getting-up followed.

Mrs. L., mother of four children; the pains in this case were sharp and lancinating, attended with much abdominal uneasiness, yet with but slight propulsive efforts. The os uteri being soft and readily

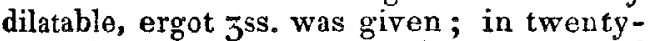
five minutes the character of the pains had altered, a strong bearing-down action was excited, and in an hour and a half, both child and placenta were delivered. 'The patient did well.

Mrs. N. First labour; the character very similar to the last. A inoderate dose of ergot, a beneficial and speedy termination. This case did favourably also.

Mrs. P. First labour. Liquor amnii discharged before uterine pains commenced, in consequence of great bodily exertion. Pains, when they came on, feeble, and productive of much abdominal distress, continued many hours without advancing the labour. Ergot, $5^{s s}$., had the effect of permanently improving the uterine efforts, both in force and duration. Os uteri freely dilated, and the bead progressed. This afterwards proved to be a case of arrest, and injurious consequences to the bladder being feared, delivery was completed with the forceps. The child, from its appearance, had been dead some days, keing somewhas putrescent. The mother had no untoward symptom during the month, with the exception of beadach, to which she was very subject.

Mrs. W. First child ; labour pains sharp, bat not propulsive, continued some hours; os uteri readily dilatable; ergot, 3ss. in powder, produced in half an hour forcible contraction, and in two hours aftes the expulsion of the foetus and placenta was accomplished. Case did well.

Mrs. T., mother of three children. Child born before my arrival ; placenta came away readily, and in an hour after, hæmorrhage supervened. The flow of blood was copious, though not violent, and the quantity lost on the whole was considerable. Cold applications to the vulva produced but trifling, if any effect. Ergot, Эij., was given in powder, and shortly after, the hand introduced in to the uterus. Uterine contraction at first very feeble, but in ten minutes after passing up the hand, and fifteen from the time of administering the ergot, the contraction was firm and powerful, the hæmorrhage rather speedily decreased, and in an hour the woman was safe.

In none of these cases, nor in others which I have met with, have I seen the least injurious effect produced upon the child. I mention this, because it has been asserted, that bad consequences to the infant fre: quently follow the exhibition of this power. ful drug. I have never witnessed any in my own practice, nor in the circle of those professional friends who have favoured me with opportunities of investigating this matter.

\section{EXTRACTION OF A BREECH.PIN FROM THE ORBIT.}

\section{To the Editor of 'THE LANCET.}

SrR,-The perusal of a case of " Extraction of a breech-pin from the orbit," recorded in your Number of the 10 th instant, brought to my recollection one of a similar nature, which fell under the care of my late respected master, Richard Moyle, Esq., of Penzance.

The accident happened prior to my entering with him as a pupil, but I remember the patient's coming to the surgery in the year 1813. I believe Mr. Moyle extracted the piece of iron a few hours after the explosion had taken place. It consisted of the entire breech-pin with the screw, two inches in length, which secures it to the stock, and which you are aware passes off at right angles from the pin itself. The whole of 